\title{
CONCIENCIA INDIVIDUAL E IMAGEN DEL MÁS-ALLĀ
}

\author{
José Luis Molina
}

Determinar cuáles son los cambios de la actitud del hombre ante la muerte durante más de mil años. Tal es el objetivo de los trabajos de Ariès. Gureviç propone aquí una explicación alternativa a la dada por el primero para la alta Edad Media ${ }^{1}$. El marco cronológico es más reducido pero el espacial es el mismo. La versión de Gureviĉ se fundamenta en un distinto tratamiento de las fuentes; es la suya una propuesta metodológica. Pero. ¿aíslan los mismos dominios? ¿son los mismos sus objetivos de investigación?

Enfin, ils s'intéressent à la conaissance de soi des hommes d'Occident, car pour cux l'évolution des représentations de la mort dévoile le lent processus de la formation de la notion d'individu. (p. 258)

Gureviĉ intenta esclarecer esta cuestión para la alta Edad Media (Conscience individuelle...). Pero una representación de la muerte y del más-allá no sólo remite al lugar que ocupa la propia biografía en la cosmovisión sino también a una determinada percepción del tiempo y a una organización del espacio de ultratumba (... et image de l'au-dela).

I A.J. Gurevic. aAu Moyen Age: conscience individuelle et image de l'audelàs, en Annales, E.S.C., 1982. 


\section{EL FIEL}

El estudio de la representación de la muerte y del más-allá en el Occidente Medieval debe observar, al parecer, la religión cristiana como referencia. El lugar común de admitir influencias «preexistentess no deja, en realidad, una huella reconocible en las exposiciones que nos ocupan. Así por ejemplo, Gureviĉ construye su argumentación a partir de una constatación previa: la escatología bíblica no es unívoca, e, incluso, puede presentársenos como contradictoria $^{2}$. Es decir, que los signos vitales del hombre altomedieval deberán buscarse en el estrecho margen que deja la ambigüedad doctrinaria en la capacidad de maniobra de un fiel. Se trata, evidentemente, de una cuestión de disponibilidad de fuentes, pero también de una cuestión epistemológica: Le Goff ( La naissance du Purgatoire, cap. II), muy de pasada y en función de otros intereses, recoge y valora las fuentes existentes para nuestro período: escritos de teólogos (a), relatos del más-allá (b) y la «liturgias (a la que habría que añadir la iconografía) (c). A fin de cuentas utiliza (a) y (b) como indicadores, desechando (c). Gureviĉ, en cambio, concede tal categoría a una combinación de (b) y (c), mientras que Ariès solamente tiene en cuenta (c). Si las conclusiones fuesen las mismas la cuestión carecería de importancia. Pero mientras (a) y (b) remiten a un juicio individual antes del Fin de los Tiempos, a una modulación del pecado y del castigo, (c) remite a un reposo, a un sueño en espera del Juicio Final. Evidentemente cette relative autonomie des différentes domaines de l'historire est un sujet de réflexion pour l'historien qui doit se résigner à ce que tout ne marche pas en histoire au même pas» ${ }^{3}$.

\section{A) Ariès, Chaunu y la muerte en la Edad Media}

Para Ariès la actitud ante la muerte en la Edad Media cambia a partir del siglo XII, cuando comienzan a aparecer en la iconografía

2 Así, mientras Mateo nos habla de un Juicio Final •à la fin des temps, après le second retour du Crist qui jugerait le genre humain, accueillerait les justes au royaume céleste et condamnerait les pécheurs au feu éternel (...) (p. 256), Lucas nos recuerda las palabras de Cristo al Buen Ladrón: «En vérité, je te le dis, aujord'bui tu seras avec moi dans le Paradis (p. 257). (Subrayado añadido).

3 LF GOF, op. cit., p. 167. 
alusiones al Juicio Final. En la Alta Edad Media se atendería solamente al retorno de Cristo, que acontecería en un futuro indeterminado, y después del cual, todos los hombres, excepto los grandes pecadores, entrarían en el Reino de los Cielos. La muerte era concebida, pues, como un letargo placentero.

Les premiers chrétiens considéraient, souligne Chaunu, que tous ceux qui croyaient au Christ seraient sauvés et que, de ce fait, le jugement ne concernait que les païens. (p. 257).

En el siglo XIII el Juicio aparece más frecuentemente representado en la iconografía. La concepción de que un juicio tiene que presidir la vida de cada individuo nos remite a su propia biografía, situada ésta en un lugar preponderante de la cosmovisión, y a la conciencia de la responsabilidad de todas las acciones y pensamientos. La vida humana aparece entonces como un largo proceso donde cada acto debe ser sancionado jurídicamente: del balance del Livre de la vie dependerá la suerte del alma del individuo en la eternidad. No obstante, este «ajuste de cuentas» no acontece en el momento de la muerte, sino el Día del Juicio Final.

Así pues, para la Edad Media, Ariès observa dos períodos. Nos interesa el primero: la muerte concebida hasta el siglo XII como placentera expectativa. Obsérvese que tal representación de la muerte aleja el protagonismo de la vida individual en la Historia Sagrada. La muerte no es aquí un espejo de la vida (balance de las acciones individuales bajo su responsabilidad), sino solamente una trasparencia de suna duración indefinida y complementaria», según las palabras de Chaunu (p. 257). Esto explicaría la efamiliaridad ante la muertes que según Ariès puede encontrarse en los documentos literarios, a los que, por otra parte, concede el rango de indicadores de la realidad".

\section{B) Una propuesta metodológica}

Acabamos de ver que según Ariès hasta el siglo XII habría una concepción de la muerte como un sueño, argumentando la aparición en la iconografía de un Dios Justiciero que separa los *'vstos de los malvados a partir de entonces. Pero, según señala Gureviĉ,

4 ARres, La Mucrie en Ocoidente Argos Vergara, Barcelona, 1982, p. 16. 
toda la Edad Media está llena de relatos de almas en pena que, *autorisés à revenir sur terre pour raconter ce qu'ils ont vu, décrivent le terribles souffrances qu'endurent les âmes des morts —-même quand il s'agit de mort récente». (p. 259). ¿Por qué — se pregunta Gureviĉ- Ariès no concede atención a estas fuentes? Tanto más cuando estos relatos entran, en su forma oral, juntamente con las representaciones iconográficas de las iglesias, en la vida espiritual del hombre de la época. Comprender su universo mental sólo es posible - continúa Gureviĉ - con una confrontación de los dos medios *et de leurs rapports réciproques» (p. 259).

Obsérvese que este planteamiento del problema sugiere aceptar implícitamente al hombre de la Alta Edad Media sujeto necesariamente a la acción de la Iglesia. Pero, ¿en qué términos? Y, volviendo a la cuestión que hemos planteado al principio, ¿por qué se escoge en un momento determinado una escatología y no la otra?:

Parmi les idées eschatologiques, la practique religieuse du Haut Moyen Age choisissait celles qui exprimaient les plus profondes tendances du comportement collectif et négligeait les autres. (p. 257)

La práctica religiosa de la Alta Edad Media obedece, pues, a elas más profundas tendencias del comportamiento colectivo». Es decir, que nos encontramos ante una sobreimpresión de dos tendencias contradictorias, una de «arriba a abajo» y otra de «abajo a arribas. ¿Cuál es el resultado?:

Les scènes eschatologiques représentées sur les portails des cathédrales des XII et XIII siècles et les scènes que rapportent les voyageurs qui ont erré dans les domaines de l'au-delà, n'appartiennent pas à des phases différentes de la perception de la mort au Moyen Age; elles expriment le statut spirituel de la personnalité dans l'espace culturel du Moyen Age, espace clivê en deux mondes. (p. 273).

Así pues, esta aparente contradicción no es más que la dualidad de la percepción del tiempo que Gureviĉ́ señala como realidad del período:

1. los relatos del más-allá ponen en primer plano la experiencia 
individual, como consecuencia de un Juicio celebrado en el lecho de muerte, sin atender a la llegada de Cristo. Se trata de la escatología de Lucas, la individual, la *petite».

2. La iconografía del más-allá (en las iglesias, «bibles de pierre») sólo hace referencia a Mateo, a la llegada de Cristo. Se trata de la escatología de la humanidad en general la «grande».

Insistimos de nuevo: el relato - oral - a cambio de un mensaje adopta la forma de actitudes y creencias colectivas pre-existentes. El predicador «traduce» su mensaje a símbolos e imágenes tradicionales para lograr su comunicación y su sanción al colocarse éste dentro del universo de referencias admitidas como legítimas. La iconografia - visual - accede a este cuerpo modificando su coherencia y haciéndose un lugar. He aquí los dos «medios» y sus relaciones recíprocas.

De cualquier forma, Gureviĉ, aún moviéndose en los dos extremos de la escatología cristiana, no abandona su margen. Fielactivo o fiel-pasivo, fiel a fin de cuentas.

Resumamos gráficamente la exposición que hasta aquí hemos hecho del artículo de Gureviĉ:

1. relatos del más-allá; 2 . iconografia.

\begin{tabular}{lcccc|c}
\hline & Medio & Acción & Escatología & Representación de la Muerte \\
\hline a visual modeladora & general & Muerte-sueño, remitida & JUICIO \\
b oral & amoldadora & individual & Juicio y ejecución, inmediata & FINAL \\
\hline
\end{tabular}

\section{C) Relatos del más-allá}

Del cuadro anterior surge una pregunta: ¿cómo se conjuga la eje cución del juicio, inmediata, con el advenimiento *por encima de toda dudas (p. 257) del Juicio Final?

Drythelm, un viajero del más-allá cuyas visiones recoge Bèda, visita acompañado por un kguide» un valle en el que infinidad de almas iban y venian de un lugar donde reinaba un frío insoportable, a otro de calor extremo. Sin embargo el guía le contesta: «non, c'est encore l'enfers (p. 262). Después visitan un alieu florit» donde innumerables almas vestidas de blanco expresaban su alegría! \&Non, il ne s'agit pas comme tu le crois du royaume célestes (p. 263). Seguidamente el guía le explica el sentido de lo que había visto: 
La vallée, bordée d'un côte par les flammes et de l'autre par un froid insupportable, était le lieu où les âmes de ceux qui ont repoussé la confession et la pénitence jusqu'à la mort subissent l'épreuve qui purge. Mais si elles se sont repenties, ne serait-ce que sur le lit de mort, elles iront toutes au jour de Jugement au royaume des cieux. Pour beaucoup d'entre elles, des requiems, des aûmones et des jeûnes les aideront et, plus encore, des messes. La fétide puits de feu est l'entrée de la Géhenne, et celui qui y est tombé, jamais n'en ressorti$\mathrm{ra}$. Le lieu fleuri est l'endroit où l'on admet les âmes de ceux qui ont accompli de bonnes actions pendant leur vide, mais n'ont pas atteint un niveau de perfection tel qu'ils méritent un accès immédiat au royaume céleste (acceso reservado a los «parfaits»). (p. 263).

El relato nos habla por tanto de cuatro «lugares»: 1) Cielo; 2) «Lieu florits; 3) «La Vallées de frío y llamas; 4) Infierno. Después de la muerte los «parfaits» irán directamente al Cielo, y los más malvados al Infierno. Para la eternidad. Pero los situados en los lugares 2 y 3 deberán esperar el día del Juicio (con bastantes garantías, a lo que parece). Nos encontramos, pues, ante una conjugación de las dos escatologías, e incorporada una concepción de purificación en el más-allá.

Conviene hacer aquí dos puntualizaciones. En primer lugar, a juzgar por la selección de relatos que nos ofrece Le Goff, solamente es posible extraer cabalmente un elemento común a todos ellos, y es la existencia de un ignis purgatoris y, quizás, de un iterim. Pero el relato de Drythelm que Gureviĉ nos presenta en calidad de ilustración es, en realidad, fruto de una discriminación, quizás justificada en función de algún criterio, en todo caso obviado. En segundo lugar, es útil distinguir, como hace Ariès', entre el estado de las almas en el más-allá y un espacio estructurado de ultratumba. Esta última elaboración es posterior y no aplicable a la Alta Edad Media. La diferencia y a la vez la conexión entre estas dos concepciones del más-allá puede expresarse en la transformación de ignis purgatoris (un estado) en purgatorium (un lugar), trasformación que tiene lugar a partir del siglo XII y fuera, por tanto de nuestro período.

\section{D) Dominios}

Lo afin («arquetipos de civilización»), nos dice Ariès, es el denomi-

5 ARIES, ele purgatoire es la cosmologie de l'au-delàs, en Annales, 1982. 
nador común de la época. Gureviç, por su parte, intenta dibujar el «universo mental solectivo de algo llamado aAlta Edad Media». Hay, pues, un común nivel de abstracción, un «algos igualador de, como mínimo, lo siguiente: 1 , el espacio (paisaje y clima: condiciones concretas de vida); 2, los individuos (sexo, lenguaje, grado de instrucción, etc.); 3, sociedades: a), o considerar la existencia de una sola sociedad (durante siglos) o un mismo tipo de sociedad; o, b), considerar irrelevante la estructura social concreta y, por ende, la situación relativa del individuo en esa estructura. ¿En qué consiste esa afinidad? ¿qué es lo que la origina? ¿El «modo de producción»? Si así fuera, se daría como respuesta a un ealgos dominante una categoría analítica que da cuenta también de concretos dominantes; pero no sería suficiente, por sí sola, para explicar la hipotética pero previsible coincidencia de concretos no englobados en el modo de producción dominante y una eactitud s, ecomportamientos o euniverso mental» así considerados. No se trata de exigir a nuestros autores que solucionen una vieja problemática, pero sí que formulen previamente sus términos; la ambigüedad de éstos da oportunidad, seguramente, a que el camello pase (por fin) por el ojo de la aguja.

Hay otra cuestión: ¿por qué Europa Occidental? Justo es decir, antes de buscar otras posibles explicaciones, que puede que se trate de una cuestión de facilidad de acceso a las fuentes, a causa del idioma, o a causa del volumen real de cantidad y grado de conservación de éstas. Pero, ¿no es coherente interpretar esta fijación del otro dominio de la investigación (Europa Occidental) en la realidad histórica postenor (el capitalismo, a fin de cuentas)? Esta pretensión a priori, ¿es legítima?

\section{II. ...ET IMAGE DE L'AU-DELÀ}

La única experiencia de estructuración del espacio de ultratumba en la Alta Edad Media la tenemos en la imagen de un puente suspendido sobre un torrente ${ }^{6}$. El resto consiste en बlugares» aislados sin conexión espacial entre ellos y sólo accesibles por medio de un ange!. guía. La organización del espacio de ultratumba-concluye Gurevici- es, por tanto, irracional.

${ }^{6}$ Una imagen de origen céltico. Cfr. LE GoF, op. eit., p. 151. 
Mais s'agit-il bien d'une topographie? Ne convient-il pas de supposer plutôt que la terminologie spatiale et ici appliquée à des phénomènes non spatiaux, qu'il est question à nouveau des angoisses et des passions, exprimées dans des formes egeométrissés» analogues? (p. 266).

Se trata de una concepción mitológica del otro mundo. Las referencias, los lugares, tienen entonces un sentido simbólico.

\section{A) El tiempo en el otro mundo}

¿Qué puede decirse de un tiempo que en principio es eterno? En primer lugar que existe paralelamente con la biografia en la tierra: el tiempo de la Iglesia cuenta tambiến en el otro mundo

Au Paradis également, les oiseaux par leur chant marquent les heures canoniques et à l'approche des messes raniment cux-mêmes les bougies. (p. 267)

En la Divina Comedia, por el contrario, el tiempo es el tiempo del observador más que el tiempo objecivo de la existencia en el másallá. Esta aplicación del tiempo terrestre al más-allá, significa, en términos de cosmovisión, que el universo está estructurado en correspondencia con la biografía individual. A efectos de representación gráfica, el tiempo de los dos mundos, en este caso, transcurriría paralelamente:

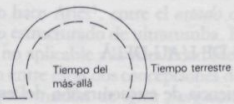

En segundo lugar, los relatos de viajeros del más-allá transmiten una percepción alineal del transcurso del tiempo; una percepción que en una representaciôn lineal del tiempo terrestre no podría representarse como una paralela a la recta de la historia, sino como una línea perpendicular: situada fuera de la representación del tiempo terrestre y, simultáneamente, en el mismo plano, el de la existencia individual. 
Au Paradis terrestre et sur terre, le temps s'écoulait différemment, et un an au pays des femmes correspondait en Irlande, à des siècles. Visiblemente, ici et là-bas, le temps revêt des qualités contraires: sur terre il conduit à la ruine de toute chose, dans le monde des bienhereux, il est impérissable. (p. 267).

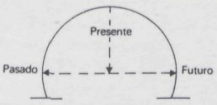

En suma, el tiempo que emana de los relatos del más-allá es un tiempo mítico, en el que el presente, el pasado y el futuro no siguen un orden racional sino que están reunidos en un econtinuum mitológico», continuum que permiten el paralelismo y la perpendicularidad, la sanción del tiempo terrestre y su inversión: «c'est le temps de l'épopée, du mythe, du conte». 